\title{
Prediction of arterial extravasation in pelvic fracture patients with stable hemodynamics using coagulation biomarkers
}

\author{
Makoto Aoki ${ }^{1 *}$, Takayuki Ogura², Shuichi Hagiwara ${ }^{1}$, Mitsunobu Nakamura² and Kiyohiro Oshima
}

\begin{abstract}
Background: Determining the presence of an active arterial hemorrhage in the acute phase is important as a treatment strategy in patients with pelvic fracture. The purpose of this study was to evaluate whether coagulation biomarkers could predict arterial extravasation, especially in pelvic fracture patients with stable hemodynamics.

Methods: We studied patients with a pelvic fracture who had a systolic blood pressure above $90 \mathrm{mmHg}$ and lactate level less than $5.0 \mathrm{mmol} / \mathrm{L}$ on hospital arrival. Patients were divided into two groups: those with arterial extravasation on enhanced computed tomography (CT) or angiography (extravasation [+] group) and those without arterial extravasation (extravasation [-] group). Coagulation biomarkers measured on arrival were statistically compared between the two groups. Predictive ability of arterial extravasation using coagulation biomarkers was evaluated by receiver-operating characteristic analyses provided area under the receiver-operating characteristic curves (AUROC) and diagnostic indicators with optimal cutoff point including sensitivity, specificity, positive and negative predictive values, and diagnostic odds ratio (DOR).

Results: Sixty patients were analyzed. Fibrin degradation products (FDP), D-dimer, prothrombin time-international normalized ratio (PT-INR), and the ratio of FDP to fibrinogen were significantly higher in the extravasation (+) group than in the extravasation (-) group (FDP, $242 \mu \mathrm{g} / \mathrm{mL}$ [145-355] vs. $96 \mu \mathrm{g} / \mathrm{mL}$ [58-153]; D-dimer, $81 \mu \mathrm{g} / \mathrm{mL}$ [41-140] vs. $39 \mu \mathrm{g} / \mathrm{mL}$ [21-75]; PT-INR, 1.09 [1.05-1.24] vs. 1.02 [0.98-1.08]; and ratio of FDP to fibrinogen, 1.06 [0. $85-2.01]$ vs. 0.46 [0.25-0.74]). The highest AUROC was with a ratio of FDP to fibrinogen of 0.777 ( $95 \%$ confidence interval, $0.656-0.898)$, and the highest predictive ability in terms of DOR was with a ratio of FDP to fibrinogen (sensitivity, 0.76; specificity, 0.76; DOR 9.90).
\end{abstract}

Conclusion: Coagulation biomarker could predict of arterial extravasation in pelvic fracture patients with stable hemodynamics.

Keywords: Trauma, Pelvic fracture, Coagulopathy, Arterial extravasation

\footnotetext{
* Correspondence: aokimakoto@gunma-u.ac.jp

'Department of Emergency Medicine, Gunma University Graduate School of

Medicine, Gunma, Japan

Full list of author information is available at the end of the article
}

(c) The Author(s). 2019 Open Access This article is distributed under the terms of the Creative Commons Attribution 4.0 International License (http://creativecommons.org/licenses/by/4.0/), which permits unrestricted use, distribution, and reproduction in any medium, provided you give appropriate credit to the original author(s) and the source, provide a link to the Creative Commons license, and indicate if changes were made. The Creative Commons Public Domain Dedication waiver (http://creativecommons.org/publicdomain/zero/1.0/) applies to the data made available in this article, unless otherwise stated. 


\section{Background}

Pelvic fracture has been shown to be an independent risk factor for death after blunt trauma $[1,2]$. It is associated with increased mortality in the blunt trauma population. In the acute phase of a pelvic fracture, arterial hemorrhage occurs from 3 to $20 \%$ of patients and induces hemodynamic instability [3-5]. The standard procedure for the detection of arterial hemorrhage has been contrast-enhanced computed tomography (CT). Arterial extravasation on contrast-enhanced CT is the most important predictor of the need for hemostatic treatment, such as transcatheter arterial embolization (TAE) [3]. However, contrast-enhanced CT has such problems as patients developing allergies to the contrast material [6], low sensitivity [7], and difficulties in radiographical interpretation $[8,9]$. Low sensitivity may lead to a high false-negative rate for arterial extravasation, which may result in a misdiagnosis and delayed mortality [8]. The exact evaluation of arterial extravasation has differed between readers, which made the interpretation of contrast-enhanced CT more difficult.

In response, we report on the predictive nature of coagulation biomarkers for arterial extravasation in patients with pelvic fracture as a supplementary method of contrast-enhanced CT [10]. However, a practical problem in our previous study was that it included all pelvic fracture patients regardless of their hemodynamic status: In a real clinical situation, most clinicians will not hesitate to undertake hemostatic treatment of pelvic fracture cases with unstable hemodynamics. Recent trauma guidelines recommend that trauma patients with unstable hemodynamics undergo immediate hemostatic treatment and not contrast-enhanced CT after pelvis X-rays [11]. Therefore, determining whether using coagulation biomarkers can be a supplementary method of contrast-enhanced CT for pelvic fracture patients with stable hemodynamics is both practical and very important.

Thus, we investigated the usefulness of coagulation biomarkers to predict arterial extravasation in pelvic fracture patients with stable hemodynamics.

\section{Methods}

\section{Study design}

A double-center, retrospective, observational study was performed. The study protocol was approved by the institutional review board of Gunma University Hospital and Japan Red Cross Maebashi Hospital. The medical records of patients with a pelvic fracture, transferred to the emergency department (ED) of these hospitals between December 2009 and December 2016, were reviewed.

\section{Patient selection}

Patients with a pelvic fracture who received prehospital treatment comprising only crystalloids and/or packed red blood cell infusions and who were tested for coagulation biomarkers on ED arrival were included. We defined exclusion criteria according to that of our previous study [10]: (1) abbreviated injury scale (AIS) scores in another region that was higher than the pelvis AIS score, (2) arterial extravasation in regions other than the pelvis, and (3) unknown time of trauma occurrence. In addition, we excluded pelvic fracture patients with unstable hemodynamics (systolic blood pressure below 90 $\mathrm{mmHg}$ on ED arrival and/or lactate level above $5.0 \mathrm{mmol} / \mathrm{L})$.

\section{Analytic variables}

The following parameters were obtained on ED arrival: patient demographics, use of anticoagulation, and/or antiplatelet drugs, trauma mechanism, vital signs at ED arrival (the Glasgow Coma Scale, systolic blood pressure, heart rate, and respiratory rate), results of blood tests (hemoglobin and lactate levels, levels of fibrin degradation products [FDP], D-dimer and fibrinogen, prothrombin time-international normalized ratio [PTINR]), AIS for each body region, injury severity score (ISS), patterns of pelvic fracture classified by Young and Burgess classification [12], World Society of Emergency Surgery (WSES) classification [13], angiography for the pelvis, treatment for pelvic fracture (TAE, external fixation, preperitoneal packing, and amount of blood transfusion within $24 \mathrm{~h}$ (in Japan, $1 \mathrm{U}$ of packed red blood cells is approximately $140 \mathrm{~mL}$ ), time course (door to CT time and door to angiography time), and mortalities (24 $\mathrm{h}$ and 30 days). With regard to analytic variables, the ratio of FDP to fibrinogen (FDP/fibrinogen) was also calculated, as with our previous study [10]. FDP and D-dimer were measured using an immunoturbidimetric method and using Cs-2000i and Cs-5100 systems (Sysmex Corporation, Kobe, Japan). It took about $15 \mathrm{~min}$ to gain the results of coagulation biomarkers by the immunoturbidimetric method.

\section{Trauma workflow of pelvic fracture patient}

During the study periods, strategies, diagnostic devices, and treatment options as to pelvic fracture were not changed. All patients who were suspected of having a pelvic fracture with stable hemodynamics underwent a contrast-enhanced CT in hospital. Contrast-enhanced CT was performed in arterial and portal venous phases. If arterial extravasation was detected on contrast-enhanced CT, we basically performed angiography. In addition, angiography was performed on patients who progressed to unstable hemodynamics and/or had a progressive retroperitoneal hematoma without obvious arterial extravasation on contrast-enhanced CT. If necessary in the acute phase after TAE, external pelvic fixation (damage control orthopedics) was performed. Basically, pelvic 
fracture patients were treated by transfusion and resuscitated by the use of resuscitation of endovascular occlusion of the aorta if necessary until TAE is completed.

\section{Definition of arterial extravasation}

Arterial extravasation was defined as extravascular high attenuating regions with attenuation similar to or greater than that of the aorta on arterial phase images, and the increase of extravasation during the portal phase compared the arterial phase. Arterial extravasation on contrast-enhanced CT and angiography was analyzed by at least one radiologist.

\section{Definition of reference standard (extravasation $[+]$ and extravasation [-])}

We divided the studied patients into two groups: The extravasation $(+)$ group was defined as having arterial extravasation on contrast-enhanced CT and/or angiography, and the extravasation (-) group was defined as not having arterial extravasation on contrast-enhanced $\mathrm{CT}$ and/or angiography. The emergency physicians and/ or the interventional radiologist made the decision to proceed to angioembolization.

\section{Statistical analysis}

Data are expressed as the median (interquartile reference; IQR). Comparisons of each parameter between extravasation $(+)$ and extravasation $(-)$ groups were performed using Mann-Whitney $U$, and chi-squared tests or Fisher's exact test. The efficacy of predicting arterial extravasation was evaluated using the area under the receiver-operating characteristic curves (AUROC), with low, medium, and high accuracy defined as $<0.7, \geq$ 0.7 to $<0.9$, and $\geq 0.9$, respectively [14]. The optimal cutoff point was defined by the maximum of the sum of sensitivity and specificity using the Youden index approach. An ordinal 2-by-2 cross-tabulation analysis for diagnostic purposes estimated sensitivity, specificity, positive and negative predictive value, positive and negative likelihood ratio, and diagnostic odds ratio (DOR). Statistical analysis was performed with IBM SPSS Statistics version 25.0 (Armonk, NY, USA). Statistical significance was defined as a two-sided $p$ value $<0.05$.

\section{Subgroup analysis}

We performed a subgroup analysis. Subgroup analysis included pelvic fracture patients with stable hemodynamics that had AIS scores in another region that was higher than the pelvis AIS score.

\section{Results}

A patient flow chart is shown in Fig. 1. Between December 2009 and December 2016, 235 patients with pelvic fracture were transferred and admitted to hospitals. Of these 235 patients, 157 patients were tested for coagulation biomarkers. Forty-nine patients with AIS scores that were greater in another region than the pelvis, three patients with an arterial extravasation in a non-pelvic region, one patient with an unknown time of trauma occurrence, and 44 patients with unstable hemodynamics were excluded. Finally, 60 pelvic fracture patients with stable hemodynamics were studied. The extravasation $(+)$ group included 35 patients: 34 with contrast extravasation on contrast-enhanced $\mathrm{CT}$, and one with contrast extravasation only found on angiography. The extravasation (-) group included 25 patients: none had contrast extravasation on contrast-enhanced $\mathrm{CT}$, and seven underwent angiography without evidence of contrast extravasation.

Patients' baseline characteristics between extravasation $(+)$ and the extravasation $(-)$ groups are shown in Table 1. The median age was $67(54-80)$ years. Median ages were $73(61-82)$ years and $63(42-70)$ years in the extravasation $(+)$ group and in the extravasation $(-)$ group, respectively). Thirty-eight patients (63.3\%) were males. Five patients $(14.3 \%)$ in extravasation $(+)$ group had use of antiplatelet drugs $(p=0.043)$. The leading cause of the trauma mechanism was motor vehicle collision (65.0\%), with falls (28.3\%) following. Concerning the vital signs taken in each ED, only the Glasgow Coma Scale was significantly lower in the extravasation $(+)$ group than in the extravasation (-) group (14 [13-15] vs. $15[14,15] ; p=0.033)$.

Concerning blood tests, there was no significant difference in the hemoglobin level between the extravasation $(+)$ group and extravasation (-) group (11.7 [10.2-13.5] g/dL vs. 12.9 [11.8-14.3] g/dL; $p=0.078)$. The FDP (242 [145-355] $\mu \mathrm{g} / \mathrm{mL}$ vs. 96 [58-153] $\mu \mathrm{g} / \mathrm{mL} ; p<0.001)$, D-dimer $(81[41-140] \mu \mathrm{g} / \mathrm{mL}$ vs. $39[21-75] \mu \mathrm{g} / \mathrm{mL} ; p=$ 0.006), PT-INR (1.09 [1.05-1.24] vs. 1.02 [0.98-1.08]; $p$ $=0.003)$ levels and ratio of FDP to fibrinogen (1.06 [0.85-2.01] vs. $0.46[0.25-0.74] ; p<0.001)$ were significantly higher in the extravasation $(+)$ group. The AUROC for FDP, D-dimer, PT-INR and the ratio of FDP to fibrinogen are shown in Table 2. The ratio of FDP to fibrinogen showed the highest AUROC (0.777 [0.656-0.898]), and the highest diagnostic ability in terms of DOR (sensitivity 0.76 , specificity 0.76 , and DOR 9.90. In a subgroup analysis, FDP and D-dimer had the highest DOR (please see Additional file 1: Table S1). The ROC curves for FDP, D-dimer, and PT-INR are shown in Fig. 2.

The extravasation $(+)$ group had a significantly higher AIS score for the head $(3[3,4]$ vs. $3[2-4] ; p=0.024)$, chest $(3[3,4]$ vs. $3[3,4] ; p=0.023)$, and the extremities and pelvis $(4[4,5]$ vs. $3[3,4] ; p<0.001$; Table 1$)$. The extravasation $(+)$ group had a significantly higher ISS (32 [25-44] vs. 14 [9-27]; $p<0.001$; Table 1 ). There was 


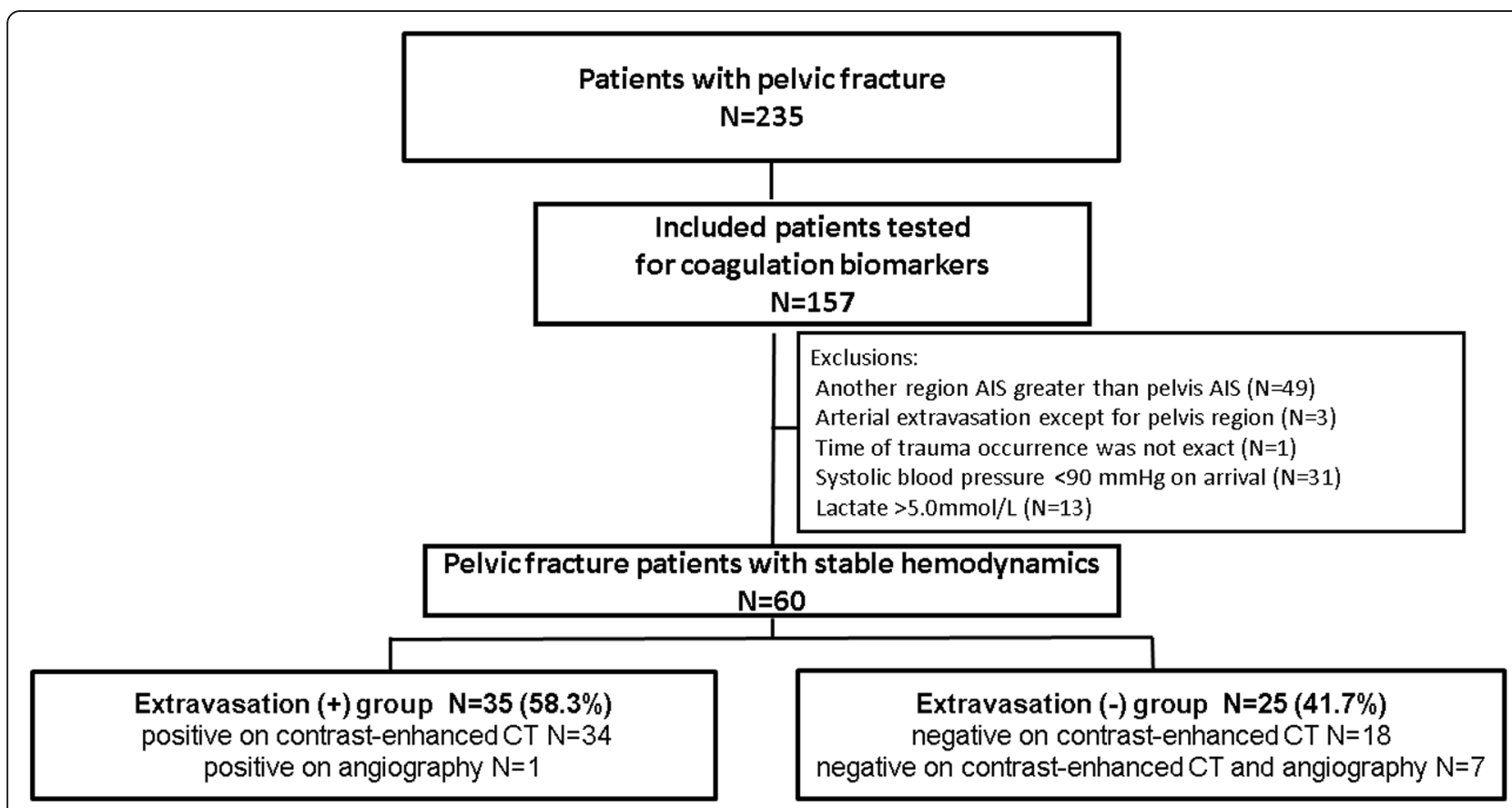

Fig. 1 Patients flow chart showing their selection and groupings. Supplemental digital content 1: AUC and cutoff points of parameters to predict arterial extravasation in pelvic fracture patients included patients with a greater AIS region other than the pelvis

a significant difference in pelvic fracture pattern in Young and Burgess classification $(p=0.021)$ and WSES classification $(p=0.011)$. As for treatment, $94 \%(33 / 35)$ of the extravasation $(+)$ group had angiography and all of the patients who had angiography underwent angiography with TAE, and $60 \%(21 / 35)$ of the extravasation (+) group had a blood transfusion within $24 \mathrm{~h}$ of the time of the injury. As for time course, the median door to CT time was 22 [18-32] minutes and median door to angiography time was 90 [72-110] minutes. All 25 extravasation (-) patients survived. Among the 35 extravasation $(+)$ patients, all patients survived within the first $24 \mathrm{~h}$; however, four patients died within 30 days from trauma occurrence for non-hemorrhagic reasons.

\section{Discussion}

\section{Brief summary}

This study demonstrated the association of arterial extravasation in pelvic fracture patients with stable hemodynamics and coagulation biomarkers. Coagulation biomarkers could predict of arterial extravasation in pelvic fracture patients with stable hemodynamics.

\section{Characteristics of coagulation biomarkers that predict arterial extravasation}

Since the usefulness of TAE for pelvic fracture was first reported [13-15], investigators have debated which patients with pelvic fracture should undergo this procedure [15-18]. Pelvic fracture patients with unstable hemodynamics were thought to require a prompt hemostatic procedure. However, it is clinically important to predict arterial bleeding in pelvic fracture patients with stable hemodynamics and to judge the necessity of hemostatic treatment before the collapse of their hemodynamics. Arterial extravasation is an important indication for needing TAE [19]. The most important finding of this study was that arterial extravasation in pelvic fracture patients with stable hemodynamics could be predicted by coagulation biomarkers. We could predict of arterial extravasation by coagulation biomarkers before CT scanning, and this perception alerted the later collapse of hemodynamics. Actually, the 15 patients of extra $(+)$ became unstable hemodynamics before completion of hemostatic treatment. The diagnostic abilities of coagulation biomarkers were medium accuracy [14] and not so high (Table 2 and Fig. 2); therefore, a combination of contrast-enhanced CT and coagulation biomarkers was thought to be realistic and practical. For instance, we could judge whether the pelvic fracture patient with stable hemodynamics should undergo enhanced $\mathrm{CT}$ or not by coagulation biomarker when we doubted that the patient has arterial extravasation from initial physical examination and/or initial pelvis X-ray.

We performed a subgroup analysis to maintain the clinical generality of the study results. For the subgroup analysis, we evaluated whether coagulation biomarkers could be applied to patients with a pelvic fracture who had a more severe injury of another body part. 
Table 1 Baseline characteristics of study patients

\begin{tabular}{|c|c|c|c|}
\hline Variables & $\begin{array}{l}\text { Extravasation }(+) \\
n=35\end{array}$ & $\begin{array}{l}\text { Extravasation }(-) \\
n=25\end{array}$ & $p$ value \\
\hline$\overline{\text { Age, }_{\text {years }}{ }^{\mathrm{a}}}$ & $73(61-82)$ & $63(42-70)$ & 0.097 \\
\hline Gender (male), $n(\%)^{\mathrm{b}}$ & $18(51.4)$ & $20(80.0)$ & 0.031 \\
\hline Use of anticoagulation, antiplatelet drugs, $n(\%)$ & $5(14.3)$ & $0(0.0)$ & 0.048 \\
\hline Trauma mechanism, $n(\%)^{\mathrm{b}}$ & & & 0.105 \\
\hline Motor vehicle & $27(77.1)$ & $12(48.0)$ & \\
\hline Fall & $7(20.0)$ & $10(40.0)$ & \\
\hline Sport & $0(0.0)$ & $1(4.0)$ & \\
\hline Others & $1(2.9)$ & $2(8.0)$ & \\
\hline \multicolumn{4}{|l|}{ Vital signs at ED } \\
\hline $\mathrm{GCS}^{\mathrm{a}}$ & $14(13-15)$ & $15(14-15)$ & 0.033 \\
\hline $\mathrm{sBP}, \mathrm{mmHg} \mathrm{a}^{\mathrm{a}}$ & $124(109-133)$ & $130(112-161)$ & 0.205 \\
\hline $\mathrm{HR}, \mathrm{bpm}^{\mathrm{a}}$ & $81(71-94)$ & $76(68-88)$ & 0.304 \\
\hline $\mathrm{RR}, \mathrm{bpm}^{\mathrm{a}}$ & $21(17-24)$ & $18(14-20)$ & 0.270 \\
\hline \multicolumn{4}{|l|}{ Blood Test } \\
\hline Hemoglobin level, $\mathrm{g} / \mathrm{dL}^{\mathrm{a}}$ & $11.7(10.2-13.5)$ & $12.9(11.8-14.3)$ & 0.078 \\
\hline Lactate level, $\mathrm{mmol} / \mathrm{L}^{\mathrm{a}}$ & $2.25(1.58-2.86)$ & $2.02(1.40-2.70)$ & 0.486 \\
\hline $\mathrm{FDP}, \mu \mathrm{g} / \mathrm{mL} \mathrm{L}^{\mathrm{a}}$ & $242(145-355)$ & $96(58-153)$ & $<0.001$ \\
\hline D-dimer, $\mu \mathrm{g} / \mathrm{mL}^{\mathrm{a}}$ & $81(41-140)$ & $39(21-75)$ & 0.006 \\
\hline Fibrinogen, $\mathrm{mg} / \mathrm{dL}^{\mathrm{a}}$ & $225(167-295)$ & $229(198-266)$ & 0.931 \\
\hline PT-INR ${ }^{a}$ & $1.09(1.05-1.24)$ & $1.02(0.98-1.08)$ & 0.003 \\
\hline Ratio of FDP to fibrinogen ${ }^{a}$ & $1.06(0.85-2.01)$ & $0.46(0.25-0.74)$ & $<0.001$ \\
\hline \multicolumn{4}{|l|}{ AIS for each region } \\
\hline Head $(n=26)^{\mathrm{a}}$ & $3(3-4)$ & $3(2-4)$ & 0.024 \\
\hline Chest $(n=25)^{\mathrm{a}}$ & $3(3-4)$ & $3(3-4)$ & 0.023 \\
\hline Abdomen $(n=12)^{a}$ & $3(2-4)$ & $3(3-4)$ & 0.540 \\
\hline Extremities and the pelvis $(n=60)^{a}$ & $4(4-5)$ & $3(3-4)$ & $<0.001$ \\
\hline $\mathrm{ISS}^{\mathrm{a}}$ & $32(25-44)$ & $14(9-27)$ & $<0.001$ \\
\hline \multicolumn{4}{|l|}{ Patterns of pelvic fracture ${ }^{b}$} \\
\hline Young and Burgess & & & 0.021 \\
\hline $\mathrm{LC} 1, n(\%)$ & $0(0.0)$ & $4(16.0)$ & \\
\hline $\mathrm{LC} 2, n(\%)$ & $12(34.3)$ & $9(36.0)$ & \\
\hline $\mathrm{LC} 3, n(\%)$ & $16(45.7)$ & $4(16.0)$ & \\
\hline $\mathrm{APC} 1, n(\%)$ & $0(0.0)$ & $0(0.0)$ & \\
\hline $\mathrm{APC} 2, n(\%)$ & $1(2.9)$ & $0(0.0)$ & \\
\hline APC3, n (\%) & $0(0.0)$ & $0(0.0)$ & \\
\hline VS, $n(\%)$ & $6(17.1)$ & $8(32.0)$ & \\
\hline WSES classification & & & 0.011 \\
\hline $1, n(\%)$ & $0(0.0)$ & $4(16.0)$ & \\
\hline $2, n(\%)$ & $29(82.9)$ & $13(52.0)$ & \\
\hline $3, n(\%)$ & $6(17.1)$ & $8(32.0)$ & \\
\hline \multicolumn{4}{|l|}{ Diagnostic procedure } \\
\hline Angiography for the pelvis, $n(\%)^{\mathrm{b}}$ & $33(94.3)$ & $7(28.0)$ & $<0.001$ \\
\hline
\end{tabular}


Table 1 Baseline characteristics of study patients (Continued)

\begin{tabular}{|c|c|c|c|}
\hline Variables & $\begin{array}{l}\text { Extravasation }(+) \\
n=35\end{array}$ & $\begin{array}{l}\text { Extravasation }(-) \\
n=25\end{array}$ & $p$ value \\
\hline TAE, $n(\%)^{\mathrm{b}}$ & $33(94.3)$ & $4(16.0)$ & $<0.001$ \\
\hline External fixation, $n(\%)^{\mathrm{b}}$ & $2(6.1)$ & $1(5.0)$ & 1.000 \\
\hline Preperitoneal packing, $n(\%)^{b}$ & $0(0.0)$ & $0(0.0)$ & N.A \\
\hline Amount of blood transfusion within $24 \mathrm{~h}$, units ${ }^{\mathrm{a}}$ & $4(0-14)$ & $0(0-0)$ & 0.002 \\
\hline \multicolumn{4}{|l|}{ Time course } \\
\hline Door to $C T$ time, min & $22(17-32)$ & $23(19-32)$ & 0.722 \\
\hline Door to angiography time, min & $92(81-116)$ & $71(53-92)$ & 0.059 \\
\hline \multicolumn{4}{|l|}{ Mortality } \\
\hline 24-h mortality, $n(\%)^{\mathrm{b}}$ & $0(0.0)$ & $0(0.0)$ & 1.000 \\
\hline 30-day mortality, $n(\%)^{\mathrm{b}}$ & $4(11.4)$ & $0(0.0)$ & 0.216 \\
\hline
\end{tabular}

${ }^{a}$ Mann-Whitney $U$ test

${ }^{b} \mathrm{X}^{2}$ test or Fisher's exact test

$E D$ emergency department, GCS Glasgow Coma Scale, $S B P$ systolic blood pressure, $H R$ heart rate, $R R$ respiratory rate, FDP fibrin degradation products, $P T-I N R$ prothrombin time-international normalized ratio, WSES World Society of Emergency Surgery, AIS abbreviated injury scale, TAE transcatheter arterial embolization, ISS injury severity score, N.A not applicable

Coagulation biomarkers were obviously affected by the presence of another anatomical injury, except for the pelvis. As a result, the predictive nature of coagulation biomarkers for arterial extravasation in pelvic fracture was decreased; however, this was of a medium level of accuracy [10]. In a clinical situation, patients with severe pelvic fracture often have another more severely injured body region. Subgroup analysis revealed that coagulation biomarkers may be useful in predicting arterial extravasation among multiple trauma pelvic fracture patients.

Possible explanations and implications: the necessity of hemostatic intervention for pelvic fracture patients with stable hemodynamics

Whether arterial bleeding in pelvic fracture patients with stable hemodynamics needs TAE is contentious. It was previously reported that only $23 \%$ of arterial extravasation cases observed on contrast-enhanced CT needed TAE [20], and we agree that all arterial extravasation cases do not need TAE. The strength of this study was that we could repeatedly predict arterial bleeding in pelvic fracture patients with stable hemodynamics and the necessity of TAE based on coagulopathy. Since the concept of trauma-induced coagulopathy has been advocated, coagulopathy accompanying trauma is associated with mortality [21-23]. Hemorrhage and coagulopathy affect each other. Therefore, hemorrhage induces more severe coagulopathy and coagulopathy induces more active hemorrhage in the absence of prompt treatment, to the point where a patient's hemodynamics will eventually collapse. In this study, the extravasation $(+)$ group showed arterial hemorrhage and coagulopathy; both of these are thought to deteriorate together. Of the extravasation (+) group with enhanced CT, $94 \%$ of patients (32/ 34) needed TAE, which indicated clinicians judged the arterial extravasation with enhanced CT could not conservatively be arrested. The high positive rate of arterial extravasation with angiography among arterial extravasation with enhanced CT may be because of coagulopathy [24]. Coagulopathy was more deteriorated in five

Table 2 AUROC of parameters to predict arterial extravasation in pelvic fracture patients

\begin{tabular}{lllll}
\hline Variables & FDP & D-dimer & PT-INR & Ratio of FDP to fibrinogen \\
\hline AUC (95\% Cl) & $0.767(0.646-0.887)$ & $0.710(0.579-0.841)$ & $0.725(0.596-0.853)$ & 0.777 (0.656-0.898) \\
Cutoff point & $179.2 \mu \mathrm{g} / \mathrm{mL}$ & $52.0 \mu \mathrm{g} / \mathrm{mL}$ & 1.05 & 0.79 \\
Sensitivity (\%) & 71 & 71 & 77 & 76 \\
Specificity (\%) & 80 & 72 & 68 & 76 \\
Positive predictive value (\%) & 83 & 78 & 77 & 77 \\
Negative predictive value (\%) & 67 & 64 & 68 & 68 \\
Positive likelihood ratio & 3.55 & 2.54 & 2.40 & 3.17 \\
Negative likelihood ratio & 0.36 & 0.40 & 0.34 & 0.32 \\
DOR & 9.86 & 6.35 & 7.06 & 9.90 \\
\hline
\end{tabular}

AUROC area under the receiver-operating characteristic curves, $C l$ confidence interval, FDP fibrin degradation products, $P T-I N R$ prothrombin time-international normalized ratio, $D O R$ diagnostic odds ratio 


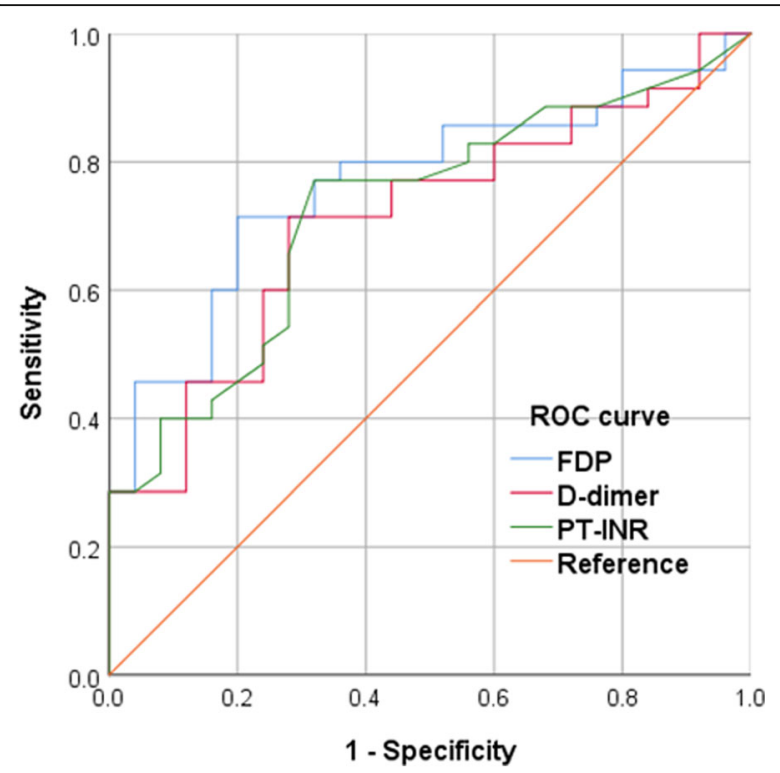

Fig. 2 Univariate receiver-operating characteristic (ROC) curve analysis for arterial extravasation. FDP fibrin degradation products, PT-INR prothrombin time-international normalized ratio, ROC receiver-operating characteristic

patients of the extravasation (+) due to anticoagulation and/or antiplatelet drugs (Table 1). Finally, 15 patients of the extravasation $(+)$ group became unstable hemodynamics; however, there was no hemorrhage-related 24-h mortality.

This study has several limitations. First, the values measured for coagulation biomarkers could have been affected by the timing of the test. In this study, we excluded a patient for whom the time of trauma was unknown; however, we did not take into account the time from trauma occurrence to testing. Second, we did not account for the amount of prehospital intravenous fluids given to patients. The administration of fluids can dilute the blood and affect the value of coagulation biomarkers. Third, we had no information about using tranexamic acid in this retrospective study. Tranexamic acid was thought to be affecting the coagulopathic state; therefore, this was an important limitation [25]. Fourth, the number of patients in this study was not large and the validation of study's result would be necessary.

\section{Conclusion}

Coagulation biomarkers could predict arterial extravasation of pelvic fracture patients with stable hemodynamics. Early recognition of coagulopathy could urge us to undertake a prompt enhanced CT and/or TAE before the hemodynamics of patients with a pelvic fracture become unstable.

\section{Additional file}

Additional file 1: Table S1. AUROC of parameters to predict arterial extravasation in pelvic fracture patients including patients with a greater AIS region other than the pelvis $(n=92)$. (DOCX $14 \mathrm{~kb})$

\section{Abbreviations}

AIS: Abbreviated injury scale; AUROC: Area under the receiver-operating characteristic curves; CT: Computed tomography; DOR: Diagnostic odds ratio; ED: Emergency department; FDP: Fibrin degradation products; IQR: Interquartile reference; ISS: Injury severity score; PT-INR: Prothrombin time-international normalized ratio; TAE: Transcatheter arterial embolization

\section{Acknowledgements}

The authors would like to thank colleagues at Department of Emergency Medicine, Gunma University Graduate School of Medicine and Advanced Medical Emergency Department and Critical Care Center, Japan Red Cross Maebashi Hospital.

Funding

The authors have no funding to report.

\section{Availability of data and materials}

The datasets used and analyzed during the current study are available from the corresponding author on reasonable request.

\section{Authors' contributions}

MA, TO, SH, MN, and KO collected the data, which MA and TO analyzed. MA and TO contributed to the interpretation of the result and drafted the manuscript. All authors read and approved the manuscript.

\section{Ethics approval and consent to participate}

The study was approved by the Institutional Review Board of Gunma University Hospital. The board waived the need for informed consent, as this was a retrospective study.

\section{Consent for publication}

Not applicable.

\section{Competing interests}

The authors declare that they have no competing interests.

\section{Publisher's Note}

Springer Nature remains neutral with regard to jurisdictional claims in published maps and institutional affiliations.

\section{Author details}

'Department of Emergency Medicine, Gunma University Graduate School of Medicine, Gunma, Japan. ${ }^{2}$ Advanced Medical Emergency Department and Critical Care Center, Japan Red Cross Maebashi Hospital, Gunma, Japan.

Received: 17 December 2018 Accepted: 8 March 2019

Published online: 19 March 2019

\section{References}

1. Schulman JE, O'Toole RV, Castillo RC, Manson T, Sciadini MF, Whitney A, Pollak AN, Nascone JW. Pelvic ring fractures are an independent risk factor for death after blunt trauma. J Trauma. 2010;68:930-4.

2. Stahel PF, Hammerberg EM. History of pelvic fracture management: a review. World J Emerg Surg. 2016;11:18.

3. Cullinane DC, Schiller HJ, Zielinski MD, Bilaniuk JW, Collier BR, Como J, Holevar M, Sabater EA, Sems SA, Vassy WM, Wynne JL. Eastern Association for the Surgery of Trauma practice management guidelines for hemorrhage in pelvic fracture--update and systematic review. J Trauma. 2011;71:1850-68.

4. Fang JF, Shih LY, Wong YC, Lin BC, Hsu YP. Repeat transcatheter arterial embolization for the management of pelvic arterial hemorrhage. J Trauma. 2009;66(2):429-35.

5. Dyer GS, Vrahas MS. Review of the pathophysiology and acute management of haemorrhage in pelvic fracture. Injury. 2006;37:602-13. 
6. Zaman SR. Previous iodinated contrast anaphylaxis in blunt abdomina trauma: management options. BMJ Case Rep. 2012. https://doi.org/10.1136/ bcr.02.2012.5919.

7. Mohseni S, Talving P, Kobayashi L, Lam L, Inaba K, Branco BC, Oliver M, Demetriades D. The diagnostic accuracy of 64-slice computed tomography in detecting clinically significant arterial bleeding after pelvic fractures. Am Surg. 2011;78:1176-82.

8. Yoshikawa S, Shiraishi A, Kishino M, Honda M, Urushibata N, Sekiya K, Shoko T, Otomo Y. Predictive ability and interobserver reliability of computed tomography findings for angioembolization in patients with pelvic fracture. J Trauma Acute Care Surg. 2018:84:319-24.

9. Fitzgerald R. Error in radiology. Clin Radiol. 2001;56:938-46.

10. Aoki M, Hagiwara S, Tokue H, Shibuya K, Kaneko M, Murata M, Nakajima J, Sawada Y, Isshiki Y, Ichikawa Y, et al. Prediction of extravasation in pelvic fracture using coagulation biomarkers. Injury. 2016:47:1702-6.

11. Tran TL, Brasel KJ, Karmy-Jones R, Rowell S, Schreiber MA, Shatz DV, Albrecht RM, Cohen MJ, DeMoya MA, Biffl WL, et al. Western Trauma Association Critical Decisions in Trauma: management of pelvic fracture with hemodynamic instability-2016 updates. J Trauma Acute Care Surg. 2016;81: 1171-4.

12. Young JW, Burgess AR, Brumback RJ, Poka A. Pelvic fractures: value of plain radiography in early assessment and management. Radiology. 1986;160(2): 445-51

13. Coccolini F, Stahel PF, Montori G, Biffl W, Horer TM, Catena F, et al. Pelvic trauma: WSES classification and guidelines. World J Emerg Surg. 2017;12:5.

14. Akobeng AK. Understanding diagnostic tests 3: receiver operating characteristic curves. Acta Paediatr. 2007;96:644-7.

15. Velmahos GC, Toutouzas KG, Vassiliu P, Sarkisyan G, Chan LS, Hanks SH, Berne TV, Demetriades D. A prospective study on the safety and efficacy of angiographic embolization for pelvic and visceral injuries. J Trauma. 2002;53: 303-8.

16. Velmahos GC, Chahwan S, Hanks SE, Murray JA, Berne TV, Asensio J, Demetriades D. Angiographic embolization of bilateral internal iliac arteries to control life-threatening hemorrhage after blunt trauma to the pelvis. Am Surg. 2000;66:858-62.

17. Fu CY, Wang YC, Wu SC, Chen RJ, Hsieh RJ, Huang HC, Huang JC, Lu CW, Huang YC. Angioembolization provides benefits in patients with concomitant unstable pelvic fracture and unstable hemodynamics. Am J Emerg Med. 2012;30:207-13.

18. Fu CY, Wu SC, Chen RJ, Wang YC, Chung PK, Yeh CC, Huang HC. Evaluation of pelvic fracture stability and the need for angioembolization: pelvic instabilities on plain film have an increased probability of requiring angioembolization. Am J Emerg Med. 2009;27:792-6.

19. Salim A, Teixeira PG, DuBose J, Ottochian M, Inaba K, Margulies DR, Demetriades D. Predictors of positive angiography in pelvic fractures: a prospective study. J Am Coll Surg. 2008;207:656-62.

20. Kuo LW, Yang SJ, Fu CY, Liao CH, Wang SY, Wu SC. Relative hypotension increases the probability of the need for angioembolisation in pelvic fracture patients without contrast extravasation on computed tomography scan. Injury. 2016:47:37-42.

21. Bozeman MC, Cannon RM, Trombold JM, Smith JW, Franklin GA, Miller FB, Richardson JD, Harbrecht BG. Use of computed tomography findings and contrast extravasation in predicting the need for embolization with pelvic fractures. Am Surg. 2012;78:825-30.

22. Juern JS, Milia D, Codner P, Beckman M, Somberg L, Webb T, Weigelt JA Clinical significance of computed tomography contrast extravasation in blunt trauma patients with a pelvic fracture. J Trauma Acute Care Surg. 2017;82:138-40.

23. Brohi $K$, Singh J, Heron M, Coats T. Acute traumatic coagulopathy. J Trauma. 2003;54:1127-30

24. Hess JR, Brohi K, Dutton RP, Hauser CJ, Holcomb JB, Kluger Y, MackwayJones K, Parr MJ, Rizoli SB, Yukioka T, Hoyt DB, Bouillon B. The coagulopathy of trauma: a review of mechanisms. J Trauma. 2008;65:748-54.

25. Meizoso JP, Dudaryk R, Mulder MB, Ray JJ, Karcutskie CA, Eidelson SA, Namias N, Cl S, Proctor KG. Increased risk of fibrinolysis shutdown among severely injured trauma patients receiving tranexamic acid. J Trauma Acute Care Surg. 2018;84(3):426-32

Ready to submit your research? Choose BMC and benefit from:

- fast, convenient online submission

- thorough peer review by experienced researchers in your field

- rapid publication on acceptance

- support for research data, including large and complex data types

- gold Open Access which fosters wider collaboration and increased citations

- maximum visibility for your research: over $100 \mathrm{M}$ website views per year

At BMC, research is always in progress.

Learn more biomedcentral.com/submissions 